\title{
Serotonin Is Involved in Autoimmune Arthritis through Th17 Immunity and Bone Resorption
}

Yasmine Chabbi-Achengli, ${ }^{*}$ Tereza Coman, ${ }^{\dagger}$ Corinne Collet, ${ }^{*}{ }^{\ddagger}$ Jacques Callebert, ${ }^{\ddagger}$ Michelangelo Corcelli, ${ }^{*}$ Hilène Lin, ${ }^{*}$ Rachel Rignault, ${ }^{\S}$ Michel Dy, ${ }^{\S}$ Marie-Christine de Vernejoul, ${ }^{*}$ and Francine Côté ${ }^{\dagger}$

From the BIOSCAR, INSERM UMR_S1132, * Hôpital Lariboisière, Unité Mixte de Recherche (UMR) 1132, Université Paris Diderot, Paris; the Laboratory of Cellular and Molecular Mechanisms of Hematological Disorders and Therapeutic Implications, ${ }^{\dagger}$ Institut Imagine INSERM U1163/CNRS ERL 8254, Hôpital Necker, Paris; the Department of Biology, ${ }^{\ddagger}$ Hôpital Lariboisière, Paris; and INSERM UMR_S1151-CNRS UMR8253, ${ }^{\S}$ Institut Necker Enfants Malades, Paris, France

\author{
Accepted for publication \\ November 24, 2015. \\ Address correspondence to \\ Marie-Christine de Vernejoul, \\ M.D., Ph.D., BIOSCAR, \\ INSERM UMR_S1132, Hôpital \\ Lariboisière, 2 rue Ambroise \\ Paré, 75010 Paris, France; or \\ Francine Côté, Ph.D., Institut \\ Imagine, INSERM U1163, \\ CNRS ERL8254, Hôpital \\ Necker, 24 blvd Montparnasse, \\ 75015 Paris, France. E-mail: \\ christine.devernejoul@aphp.fr or \\ francine.cote@parisdescartes.fr.
}

\begin{abstract}
Rheumatoid arthritis is a chronic disease that results in a disabling and painful condition as it progresses to destruction of the articular cartilage and ankylosis of the joints. Although the cause of the disease is still unknown, evidence argues that autoimmunity plays an important part. There are increasing but contradictory views regarding serotonin being associated with activation of immunoinflammatory pathways and the onset of autoimmune reactions. We studied serotonin's involvement during collagen-induced arthritis in wild-type and $T p h 1^{-/-}$mice, which have markedly reduced peripheral serotonin levels. In wild-type mice, induction of arthritis triggered a robust increase in serotonin content in the paws combined with less inflammation. In Tph1-/- mice with arthritis, a marked increase in the clinical and pathologic arthritis scores was noticed. Specifically, in $T p h 1^{-/-}$mice with arthritis, a significant increase in osteoclast differentiation and bone resorption was observed with an increase in IL-17 levels in the paws and in Th17 lymphocytes in the draining lymph nodes, whereas T-regulatory cells were dampened. Ex vivo serotonin and agonists of the 5-HT2A and 5-HT2B receptors restored IL-17 secretion from splenocytes and Th17 cell differentiation in Tph1 ${ }^{-/-}$mice. These findings indicate that serotonin plays a fundamental role in arthritis through the regulation of the Th17/ T-regulatory cell balance and osteoclastogenesis. (Am J Pathol 2016, 186: 927-937; http:// dx.doi.org/10.1016/j.ajpath.2015.11.018)
\end{abstract}

Recent studies of the neuroendocrine and immune systems indicate that neuropeptides, neurotransmitters, hormones, and cytokines, as well as their respective receptors, can act as common mediators to mount appropriate responses to shifting external insults. ${ }^{1,2}$ Serotonin (5-hydroxytryptamine, or 5-HT) is a recognized neurotransmitter and neurohumoral agent with vasoactive and growth factor-like properties. ${ }^{3}$ Although 5-HT is well known for its role as a neurotransmitter in the central nervous system, increasing evidence substantiates the fact that nonneuronal 5-HT is involved in numerous functions. ${ }^{4}$ The rate-limiting enzyme responsible for 5-HT synthesis, tryptophan hydroxylase (TPH), catalyzes the conversion of tryptophan into 5-HT and is found only in 5-HT-producing cells. TPH exists in two forms. TPH2 is predominantly found in the central nervous system, whereas TPH1 is found mainly in peripheral tissues. 5-HT does not cross the blood brain barrier, and all the 5-HT produced in peripheral tissues is catalyzed by TPH1. ${ }^{5-7}$ Studies have found that the immune system can be regulated by the action of 5-HT on immune cells expressing 5-HT receptors (5-HTRs). Such receptors are present on the surface of $\mathrm{T}$ cells, dendritic cells, natural killer cells, and monocytes. ${ }^{8,9}$ A recent investigation reported that Tphl deficiency intensifies inflammation in experimental autoimmune encephalomyelitis, impairs allograft tolerance, and increases the immune suppression of tumors. ${ }^{10}$

\footnotetext{
Supported by Arthritis Courtin's Fundation, la Fondation pour la Recherche Médicale, le Centre National de la Recherche Scientifique, l'Université Paris Descartes, and a fellowship from Institut Imagine (T.C.). Y.C.-A. and T.C. contributed equally to this work.

M.-C.d.V. and F.C. contributed equally to this work as senior authors. Disclosures: None declared.
} 
Collagen-induced arthritis (CIA) is an established murine model of rheumatoid arthritis (RA) that recapitulates most features of the human disease. ${ }^{11}$ In CIA, inflammation induces cartilage and bone destruction as well as the activation of osteoclasts, which are both key effectors of the disease. In this model, $\mathrm{CD} 4^{+} \mathrm{T}$ cells are required to initiate arthritis and to stimulate osteoclast activity. ${ }^{12,13}$

Our aim was to identify the effect of 5-HT deficiency during the clinical expression of arthritis, bone destruction, and inflammatory response in a murine model of RA. We further determined whether 5-HT could directly regulate the immune response in CIA.

\section{Materials and Methods}

\section{Animals and the Induction of CIA}

All of the experiments were approved by the Comite d'Ethique pour l'Expérimentation Animale de Lariboisière Villemin (Medical School, Paris Diderot University) and complied fully with French government animal welfare policy (CEEALV/2012-07-01). Targeted mutagenesis of the Tphl gene has been described elsewhere. ${ }^{5}$ Transgenic and wild-type (WT) animals were derived from pure C57BL/6J genetic backgrounds. At 10 weeks of age, mice were immunized as previously described with some modifications. ${ }^{14}$ Briefly, mice received an s.c. injection at the base of the tail of $100 \mathrm{mg}$ of native chicken type II collagen (Chondrex) emulsified in Freund's complete adjuvant. An s.c. boost of $100 \mathrm{mg}$ of type II collagen in Freund's complete adjuvant was given 21 days later. The WT and $T p h 1^{-/-}$mice were evaluated at day 0 (baseline) and after the onset of arthritis at day 36 (peak of inflammation) and day 54 (end of the plateau) after the first injection. Naive animals without arthritis were evaluated after being sacrificed at the same time points.

\section{Assessment of Arthritis}

From 27 days after immunization to the end of the experiment, the paws of mice with CIA were scored three times a week under blind conditions (Y.C.A.). The clinical severity of the arthritis was scored as follows: 0, normal; 1, erythema; 2, swelling; and 3, deformity or swelling of the entire paw (ie, toes, tarsus, and ankles). The joint scores were then summed to obtain the total arthritis score of the 4 limbs, yielding scores of 0 to 30 per animal. In each group, the mean of the total arthritis score was calculated three times a week to monitor the severity of CIA.

\section{Histologic Score}

At day 54 after the injection, the mice were sacrificed and their legs dissected free of muscles and processed for histologic studies. At least four serial sections were cut from each paw to ensure extensive evaluation of the arthritic joints by hematoxylin and eosin and safranin-O staining.
Each section was evaluated under blind conditions (Y.C.A.) using four parameters ( 0 - to 3-point scale for each parameter): synovial inflammation and thickness, synovial invasion of the joint, cartilage erosion, and bone erosion. The total histologic score consisted of the sum of the four parameters.

\section{Microarchitecture and Histomorphometry}

At day 54, the animals were sacrificed and the femur (distal metaphysis) and the paws scanned using a high-resolution micro-computed tomography (micro-CT) system (Micro CT-40; SCANCO Medical AG, Brüttisellen, Switzerland) and analyzed using the three-dimensional morphometry evaluation program to determine the bone structure parameters (bone volume/tissue volume, trabecular separation for the femur and bone volume/tissue volume, medullary volume and bone surface/bone volume for the paws). At day 36, the knee was embedded in methylmethacrylate. Tartrate-resistant acid phosphatase staining was performed to evaluate osteoclast numbers.

\section{Biochemical Marker of Bone Resorption}

The urine was collected before and 36 days after immunization. D-pyridinoline was measured using the IMMULITE Pyrilinks-D in vitro diagnostic reagent (Metra Biosystem, Mountain View, CA). To correct the variations due to the urinary flow, the D-pyridinoline results were normalized using the urinary creatinine concentration (ADVIA System, Siemens Healthcare GmbH, Erlangen, Germany).

\section{Osteoclastogenesis}

Spleen cells were isolated from WT and $T p h 1^{-1-}$ mice at baseline and on day 36. Osteoclastogenesis was performed and assessed as previously described ${ }^{14}$ in the presence of macrophage colony-stimulating factor and at increasing concentrations $(25,50$, and $100 \mathrm{ng} / \mathrm{mL})$ of receptor activator of NF-אB ligand(RANK-L; Peprotech, Rocky Hill, NJ).

\section{Immunoassay of Serum Anti-CII Antibody Levels}

Serum was collected from the blood samples taken at day 36. Anti-CII IgG1, IgG2a, and IgG2c levels were measured using enzyme-linked immunosorbent assay (Chondrex), according to the manufacturer's instructions.

\section{Cytokine Measurements}

Mice were sacrificed 36 days after immunization. One paw from each mouse was collected to measure the cytokine secretion in the whole joint. After dissection of the soft tissue, $150 \mathrm{mg}$ of paw (almost the whole joint) was ground up in lysis buffer (Invitrogen, Carlsbad, CA), and the cytokine content was determined. Tumor necrosis factor (TNF)- $\alpha$, interferon (IFN)- $\gamma$, IL-17, IL-4, IL-6, and transforming growth factor (TGF)- $\beta$ were measured using 
A

Clinical score

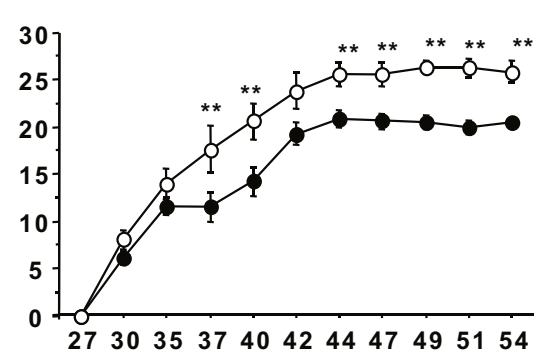

B

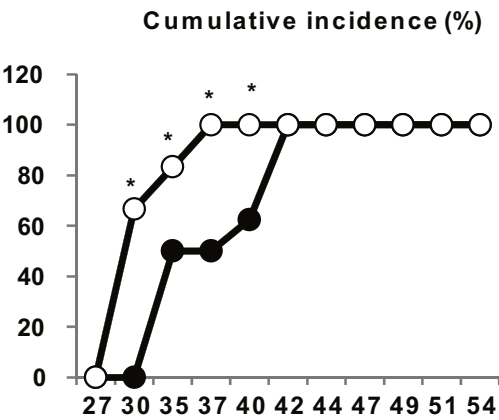

C

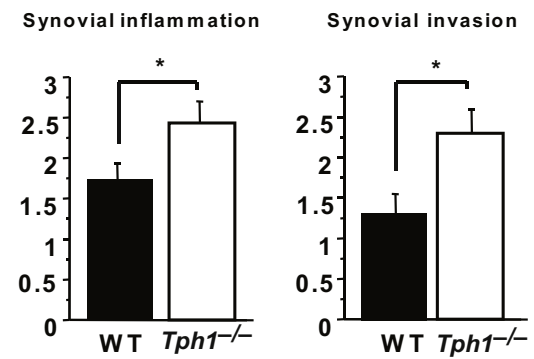

Bone erosion

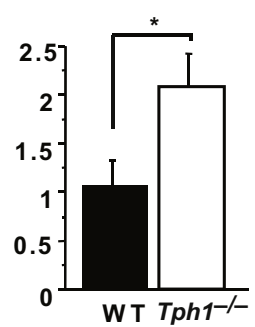

Cartilage erosion

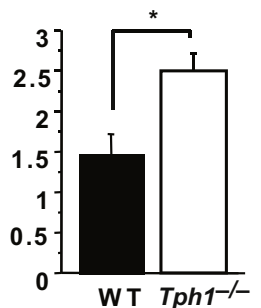

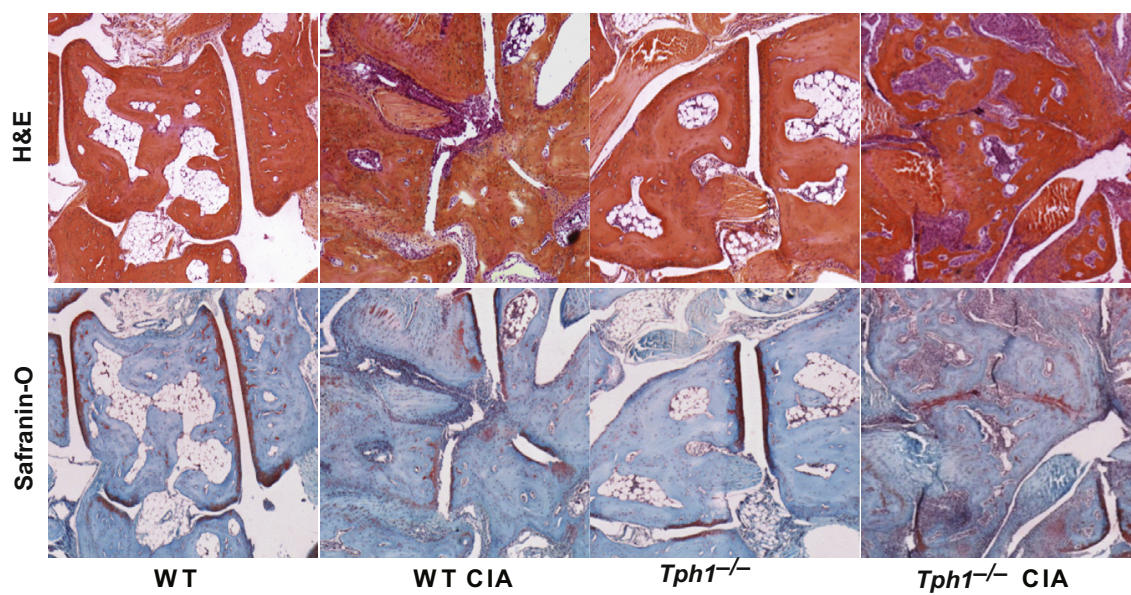

Figure 1 The absence of Tph1 promotes joint inflammation in collagen-induced arthritis (CIA). A: Clinical arthritis scores were determined at different time points during the experimental period in the paws of wild-type (WT; closed circles) and $\mathrm{Tph}^{-1-}$ (open circles) mice. One of the three independent experiments is shown. B: Cumulative incidence of CIA. C: Tissue sections of the joints of WT and Tph1 ${ }^{-/}$mice were stained with hematoxylin and eosin (H\&E) and safranin-0, and histology scores for features of arthritis were determined. Data are expressed as means \pm SEM (A). $n=7$ to 8 mice per group (A and C). ${ }^{*} P<0.05,{ }^{* *} P<0.005$. Original magnification, $\times 20(C)$. enzyme-linked immunosorbent assays (R\&D Systems, Minneapolis, MN). Levels were expressed in picograms per milliliter.

\section{Serotonin Measurement}

After dissection of the soft tissue, the whole joint was ground up in $10^{-2} \mathrm{~mol} / \mathrm{L}$ hydrochloric acid and sonicated in 10 volumes $(\mathrm{v} / \mathrm{w})$ of $0.1 \mathrm{~N}$ perchloric acid/ $0.05 \%$ disodium EDTA/ $0.05 \%$ sodium metabisulfite. After centrifugation at $22,000 \times g$ for 20 minutes at $4{ }^{\circ} \mathrm{C}$, the supernatants were collected and filtered through a 10-kDa membrane (Nanosep, Pall Corp., Port Washington, NY) by centrifugation at $7000 \times g$. Then a $20-\mu \mathrm{L}$ aliquot was analyzed for 5 -HT by fluorometric detection (Kema NV, Arnhem, the Netherlands). The results are reported in femtomoles of 5-HT per milligram of paw.

\section{Flow Cytometry}

Cells from inguinal and axillary lymph nodes from WT and Tph1 ${ }^{-1-}$ mice were obtained by pressing the tissues through a $100-\mu \mathrm{m}$ mesh and washed in phosphate-buffered saline and $2 \%$ fetal bovine serum (PBS-FBS). Cells were preincubated with CD16/CD32 monoclonal antibody (clone $2.4 \mathrm{G} 2$ ) to block Fc $\gamma$ receptors and then incubated with the indicated monoclonal antibody conjugates for 30 minutes in a total volume of $50 \mu \mathrm{L}$ of PBS-FBS. For intracellular cytokine staining, cells were stimulated for 4 hours in complete RPMI 1640 medium (10\% FBS, $50 \mathrm{IU} / \mathrm{mL}$ of penicillin, $50 \mathrm{IU} / \mathrm{mL}$ of streptomycin, $1 \%$ HEPES, $5 \times 10^{-5}$ $\mathrm{mol} / \mathrm{L}$ of $\beta$-Mercaptoethanol; Thermo Fisher Scientific, Villebon, France) in the presence of $50 \mathrm{ng} / \mathrm{mL}$ of phorbol 12 -myristate 13 -acetate, $500 \mathrm{ng} / \mathrm{mL}$ of ionomycin, and 10 $\mu \mathrm{g}$ of brefeldin A (Sigma-Aldrich, St Louis, MO). Matched 


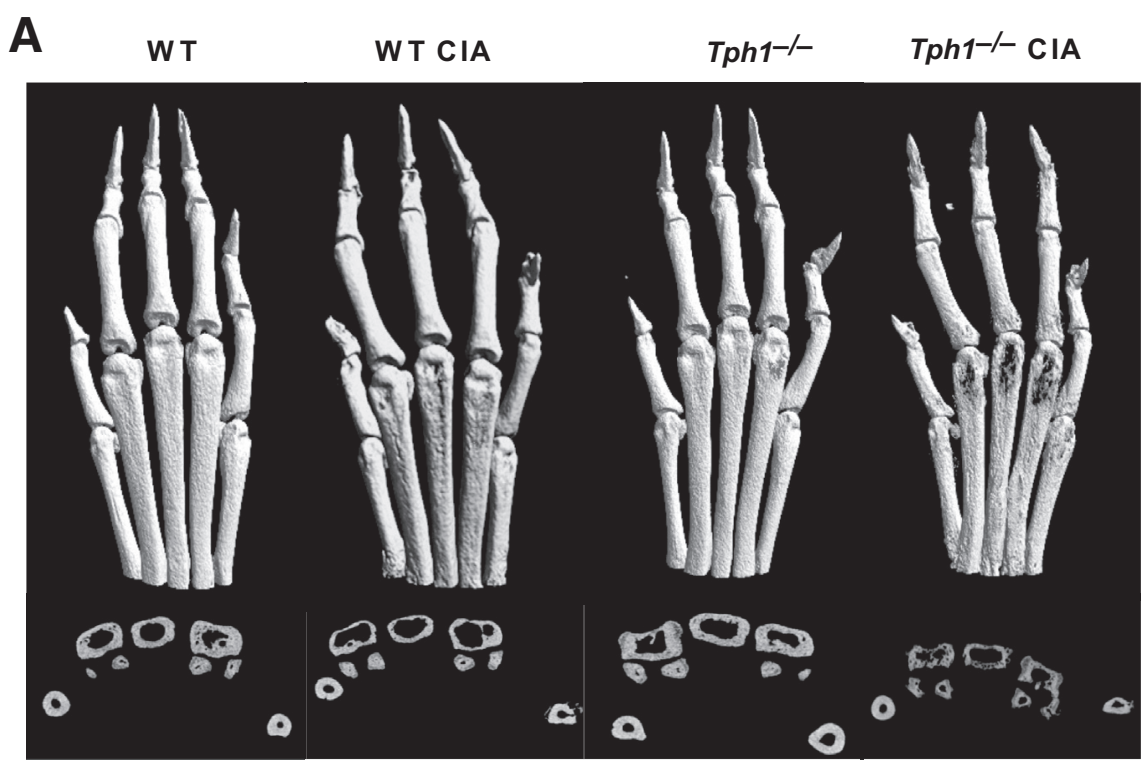

B
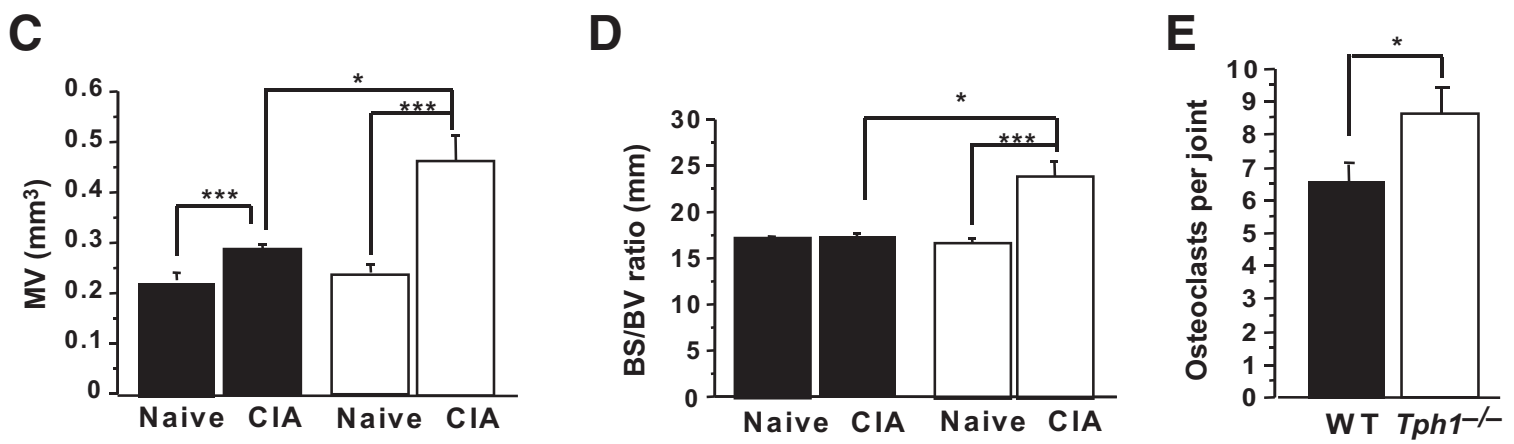

Figure 2 Joint erosion and osteoclast numbers are increased in $T p h 1^{-1-}$ mice. A: Representative three-dimensional reconstructions of micro-computed tomography images at baseline of the paws of naive or collagen-induced arthritis (CIA) wild-type (WT) and Tph1 ${ }^{-/}{ }^{-}$mice 54 days after the first CII immunization. Bone volume/tissue volume (BV/TV) ratio (B), medullary volume (MV) (C), and bone surface/bone volume (BS/BV) ratio (D) were measured in each paw in naive and CIA WT mice (black bars) and Tph1 ${ }^{-1}{ }^{-}$mice (white bars). E: Tartrate-resistant acid phosphatase staining of section of knees was performed to identify osteoclasts in the joint. The number of osteoclasts per joint was determined. ${ }^{*} P<0.05$, $* * P<0.005$, and $* * * P<0.0005$.

controls were incubated with $10 \mu \mathrm{g}$ of brefeldin A alone. Intracellular staining was performed on fixed cells in a permeabilization solution (eBioscience Inc., San Diego, CA). The antibodies used were anti-CD3 (17A2), anti-CD4 (GK1.5), anti-CD25 (PC61.5), anti-IL-17 (17B7), antiFoxP3 (FJK-16s), and anti-ROR $\gamma \mathrm{t}$ (B2D) (eBioscience Inc., San Diego, CA). Live cells were gated using Live/Dead fixable stains kit (Life Technologies, Carlsbad, CA). Cells were analyzed on a FACS CantoII (BD Biosciences), coupled with FlowJo software version X.0.7 (Tristar, San Carlos, CA).

For Tph1 flow cytometry analysis, human $\mathrm{T}$ lymphocytes were cultured with or without $10 \mu \mathrm{mol} / \mathrm{L}$ of parachlorophenylalanine (PCPA), and the presence of the Tph1 protein was assessed by FACS analysis using the Tph1 antibody. Cells were stained with the tryptophan hydroxylase antibody (ab52954; Abcam, Cambridge, England) according to the manufacturer's protocol. Briefly, cells were fixed with $80 \%$ methanol (5 minutes) and then permeabilized with $0.1 \%$ PBS-Tween for 20 minutes. Cells were then incubated in $1 \times \mathrm{PBS} / 10 \%$ normal goat serum followed by the antibody (ab52954, 1:100 dilution) for 30 minutes at room temperature. The secondary antibody used was DyLight 488 goat anti-rabbit $\operatorname{IgG}(\mathrm{H}+\mathrm{L})(\mathrm{ab} 96899)$ at 1:500 dilution for 30 minutes at room temperature. Isotype control antibody was rabbit IgG (monoclonal) used under the same conditions. Cells were analyzed on a FACS Gallios BD (Beckman Coulter Inc., Brea CA), coupled with FlowJo software version X.0.7 (Tree Star, Ashland, OR).

\section{Isolation of Total RNA and a RT-PCR}

Total RNAs were isolated from the paws using Trizol reagents (Invitrogen) according to the manufacturer's instructions. The total RNAs were then reverse transcribed into cDNA using the high-capacity cDNA verso kit (Applied Life Technologies, Foster City, CA). The mRNA expression levels of Tphl were analyzed by means of a Taqman assay (Thermo Fisher Scientific). 
A

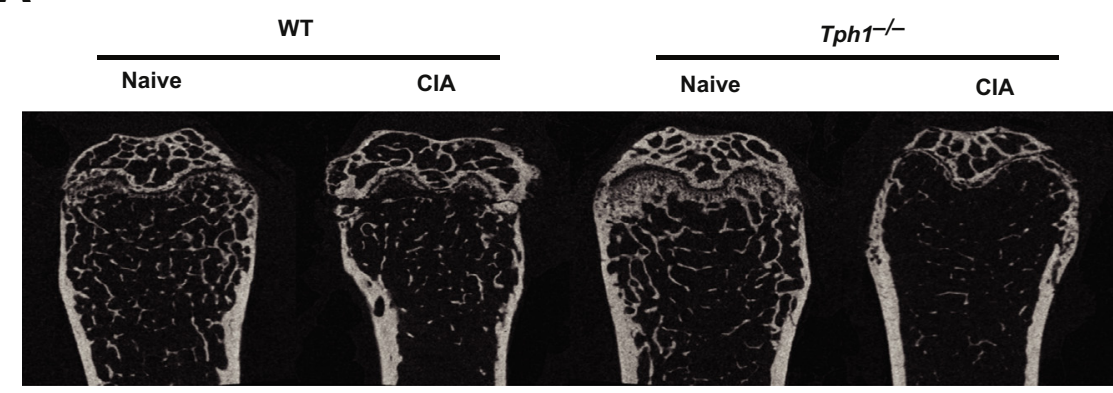

B

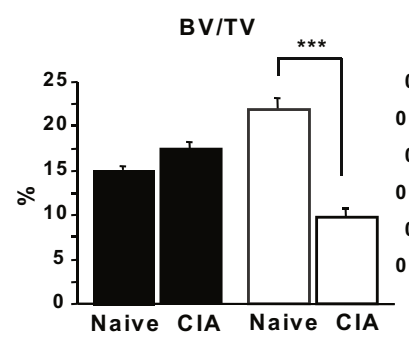

C

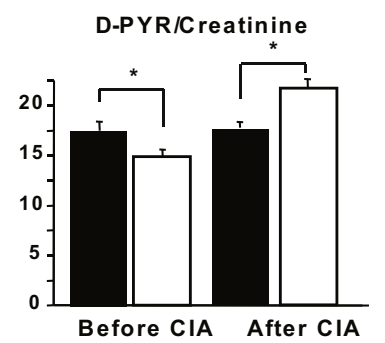

D
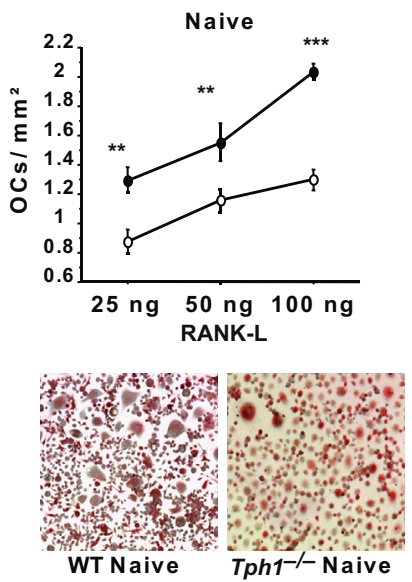

E
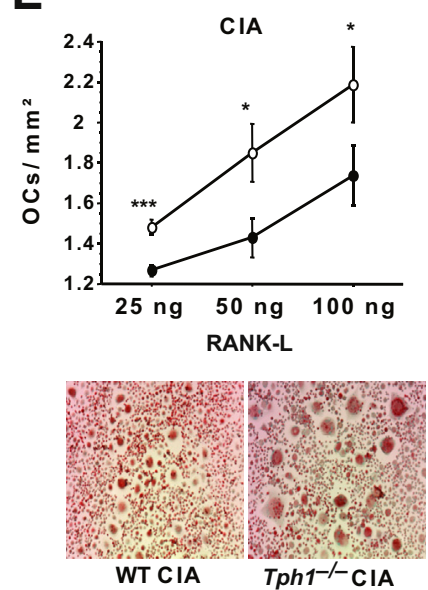

Figure 3 Arthritic $T p h 1^{-/-}$mice have increased generalized resorption and osteoclast differentiation. A: Representative three-dimensional reconstructions of micro-computed tomography images of metaphyseal femur of naive or collageninduced arthritis (CIA) wild-type (WT) and Tph1-/mice at 54 days after the first CII injection. B: Bone volume/tissue volume (BV/TV) ratio and trabecular separation were measured in each femur at baseline (naive) and 54 days after immunization (CIA) in WT (black bars) and Tph1 ${ }^{-/}$mice (white bars). C: Biochemical markers of resorption: urinary D-pyridinoline (D-PYR) crosslinks normalized versus the amount of creatinine present was measured before and at day 36 after the induction of CIA in WT and Tph1 $1^{-/}$mice. D: Counts of osteoclasts (OCs) in WT (closed circles) and Tph1-/- (open circles) cultures. E: Osteoclastogenesis was assessed in WT (closed circles) and $\mathrm{Tph}^{-1-}$ (open circles) spleen cells cultured with dialyzed serum without $5-\mathrm{HT}$ in the presence of $25 \mathrm{ng} / \mathrm{mL}$ of macrophage colonystimulating factor for 4 days and of macrophage colony-stimulating plus different doses of receptor activator of NF- $\mathrm{B} B$ ligand (RANK-L; 25, 50, and $100 \mathrm{ng} / \mathrm{mL}$ ) for an additional 5 days. Data are presented as means \pm SEM of three independent experiments. $n=7$ WT mice and $n=8 \operatorname{Tph}^{-1}{ }^{-}$mice (B). ${ }^{*} P<0.05,{ }^{*} P<0.005$, and ${ }^{* * *} P<0.0005$.
The probes were purchased from Applied Biosystems (Foster City, CA).

\section{Spleen Cell Cultures}

Splenocytes were collected from CIA animals on day 36, seeded at $3 \times 10^{6}$ cells per $\mathrm{mL}$ in alpha minimum essential medium supplemented with $8 \%$ dialyzed FBS, and cultured for 72 hours with $50 \mu \mathrm{g} / \mathrm{mL}$ of chicken CII (Chondrex) in the presence or absence of different doses of 5-HT (SigmaAldrich). The supernatants were then collected and IL-17 concentrations were determined by enzyme-linked immunosorbent assay (R\&D Systems).

\section{Chemicals}

Serotonin (5-HT) and PCPA were purchased from Sigma-Aldrich. 5-HT2A agonists/antagonists (PNU-22394,
MDL100907) and 5-HT2B agonists/antagonists (BW 723C86, RS127445) were from Sigma-Aldrich and Tocris Bioscience (Bristol, England).

\section{In Vitro T-Cell Differentiation}

For each experimental condition, cells from inguinal and axillary lymph nodes from WT and $T p h 1^{-1-}$ mice were plated at a concentration of $2.5 \times 10^{5}$ cells in $200 \mu \mathrm{L}$ per well in a 96 U-shaped well plate. Cells were stimulated for 3 days in complete RPMI 1640 medium with $10 \%$ fetal calf serum, $5 \mu \mathrm{g} / \mathrm{mL}$ of soluble anti-CD28 (clone 37.51, BD Pharmigen, Franklin Lakes, NJ), and $100 \mathrm{IU} / \mathrm{mL}$ of IL-2 (Immunotools $\mathrm{GmbH}$, Friesoythe, Germany) in plates previously coated with $5 \mu \mathrm{g} / \mathrm{mL}$ of anti-CD3 (clone 145.2C11, eBioscience Inc.) with or without 0.25 to $0.5 \mathrm{ng} / \mathrm{mL}$ of mouse TGF- $\beta$ (R\&D Systems) and/or 0.2 to $5 \mu \mathrm{g} / \mathrm{mL}$ of recombinant 5-HT (Sigma-Aldrich). When specified flow 
cytometer sorted $\mathrm{CD} 4{ }^{+}$Foxp3 $3 \mathrm{GFP}^{-}$, cells were stimulated for 3 days with plate coated with anti-CD3/anti-CD28 antibodies alone or in the presence of $0.5 \mathrm{ng} / \mathrm{mL}$ of TGF- $\beta$ with or without antagonists of 5-HT receptors.

\section{Human T Lymphocytes}

$\mathrm{CD}^{+} \mathrm{T}$ cells were purified from peripheral blood mononuclear cells from healthy donors (Convention Etablissement Français du Sang 14/EFS/018) by positive CD4 microbeads labeling (CD4 $+\mathrm{T}$ cell isolation kit, Milteny Biotec, Bergisch Gladbach, Germany). Cells were stimulated for 3 days in complete RPMI 1640 medium with $10 \%$ fetal calf serum, in $96 \mathrm{U}$-shaped well plates previously coated with $10 \mu \mathrm{g} / \mathrm{mL}$ of anti-CD3 (clone UCHT1, R\&D Systems) and anti-CD28 (clone 37407, $\mathrm{R} \& D$ Systems) with or without PCPA.

\section{Statistical Analysis}

The results are expressed as means \pm SEM. Comparison tests were performed using analysis of variance for repeated measurements followed by protected Fisher's least significant difference test when appropriate. Statistical analyses were performed using Prism software version 5.01 (GraphPad Software, La Jolla, CA).

\section{Results}

Greater Severity and Earlier Onset of CIA Observed in Tph $^{-/-}$Mice

$T p h 1^{-1-}$ mice had a higher clinical score of arthritis from day 37 after immunization until they were sacrificed on day 54 (Figure 1A). Tphl ${ }^{-1-}$ mice also had accelerated onset of the disease with a higher incidence of arthritis from day 30 to day 37 (Figure 1B). Histologic assessment of arthritic joints using hematoxylin and eosin staining revealed a higher arthritis score on $T p h 1^{-1-}$ mice as indicated by greater joint inflammation and invasion as well as an increased erosion of bone and cartilage in the $T p h 1^{-1-}$ mice (Figure 1C). Safranin-O staining revealed marked proteoglycan depletion in the $T p h 1^{-1-}$ mice with arthritis.
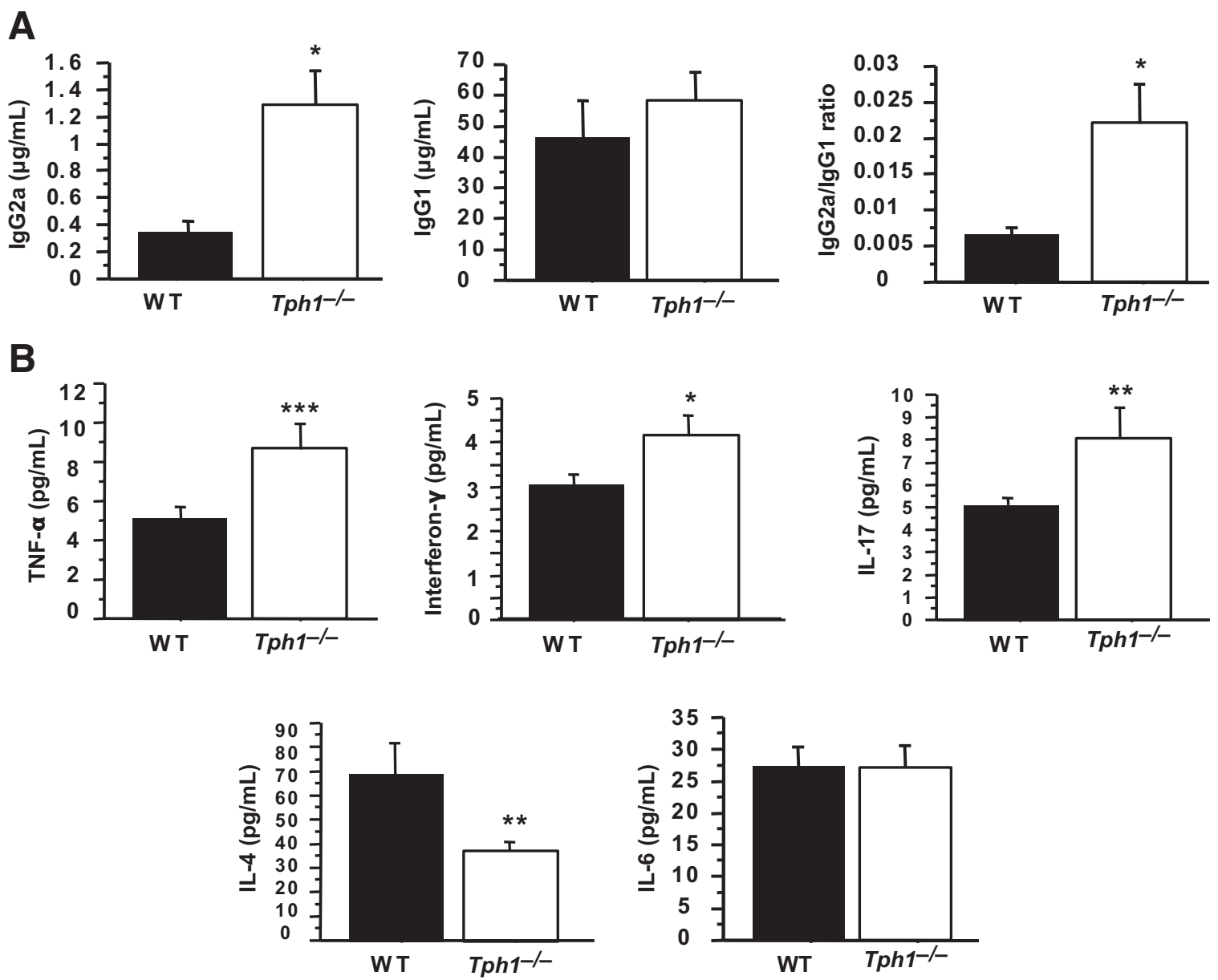

Figure 4 Arthritic $\mathrm{Tph}^{-/-}$mice have increased proinflammatory cytokine production. A: The levels of IgG2a and IgG1 anti-CII antibodies in the serum were measured on day 36 in Tph1 ${ }^{-1-}$ (white bars) and wild-type (WT) mice (black bars). B: The levels of different cytokines were assessed in the paws to evaluate the effect of the absence of Tph1 on systemic cytokine concentrations during the acute phase of the disease (D36) in Tph1 ${ }^{-/}{ }^{-}$mice and WT mice. Data are expressed as means \pm SEM. $n=14 \mathrm{Tph}^{-/-}$mice and $n=17$ WT mice. ${ }^{*} P<0.05$, ${ }^{* *} P<0.005$, and ${ }^{* * *} P<0.0005$. 
A

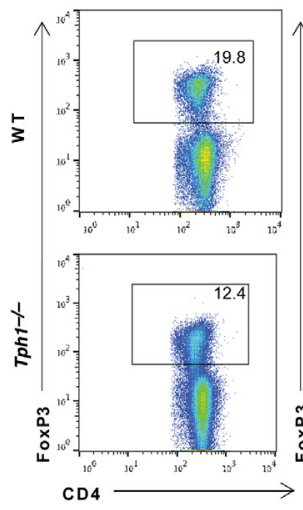

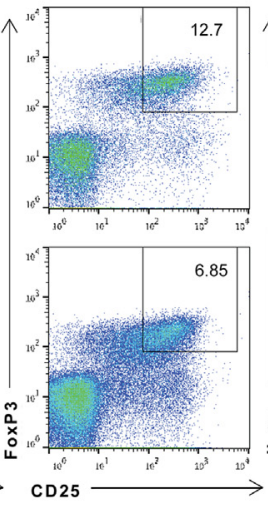

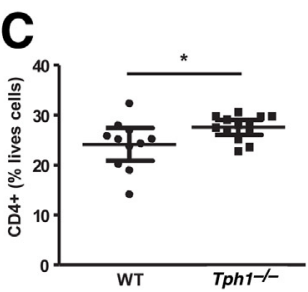

B

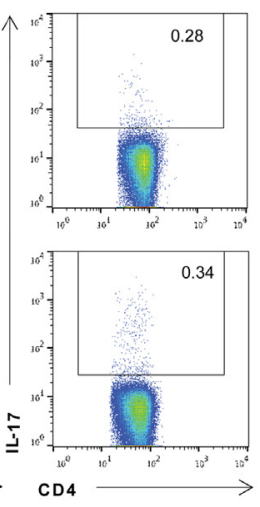

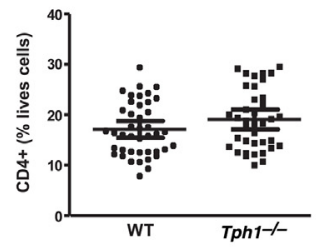
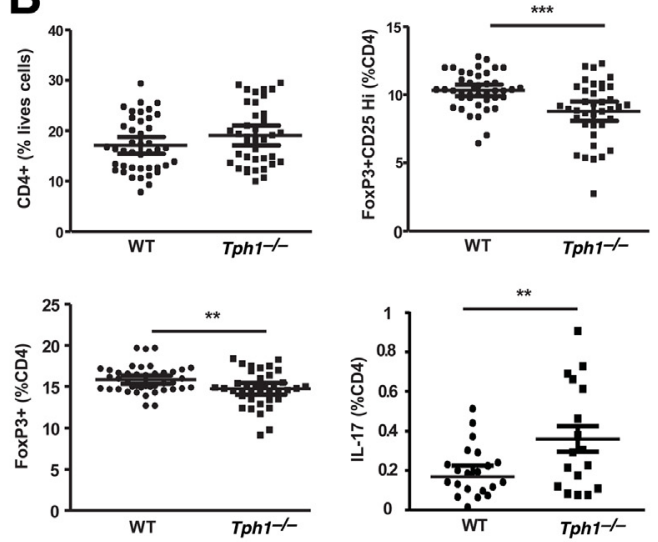

Figure 5 Tph1 ${ }^{-/-}$mice have an imbalance between T-regulatory (Treg) cells and Th17 cells. A: Lymph node T cells from collagen-induced arthritis (CIA) wild-type (WT) or Tph1 $1^{-1-}$ mice were stained with antibodies against CD4, CD25, FoxP3, and IL-17. A plot from one representative experiment shows the frequencies of $\mathrm{CD}_{25}{ }^{+}, \mathrm{FoxP}^{+}$, and IL- $17^{+}$cells among $\mathrm{CD}^{+}$T cells. B: Each data point represents an individual animal. C: Lymph node T cells from naive WT or $T p h 1^{-1-}$ mice were stained with antibodies against CD4, CD25, and FoxP3. Data are expressed as means \pm SEM (B and C). $n=21$ to 42 WT mice and $n=17$ to $38 \mathrm{Tph}^{-1-}$ mice (A); $n=11$ naive WT and $n=13 \mathrm{Tph}^{-1-}$ mice (C). ${ }^{*} P<0.05$, ${ }^{*} P<0.005$, and ${ }^{* * *} P<0.0005$.

\section{Severe Osteoclastic Joint Erosion in Arthritic Tph1 $1^{-/-}$ Mice}

An accurate evaluation of bone erosion was performed by micro-CT of mice paws. The images showed increased periarticular erosion around the metacarpal joints of the arthritic $T p h 1^{-/-}$joints (Figure 2A). An objective quantification of the images was established from the bone volume/tissue volume (BV/TV) ratio measured on sections of the metacarpal bones (Figure 2B). In the context of arthritis, the BV/TV ratio was significantly decreased in $T p h 1^{-1-}$ mice $(-4.13 \%$ WT versus $-17.29 \% \mathrm{Tphl}^{-1-} ; P=0.04$ ), whereas the medullary volume was significantly greater compared with the WT mice (Figure 2C). The bone surface/bone volume ratio revealed an increase in the eroded surfaces with arthritis solely in $T p h I^{-1-}$ mice (Figure 2D). To evaluate the number of osteoclasts, we stained the undercalcified sections of the knees for tartrateresistant acid phosphatase and observed more osteoclasts in the arthritic joints of $T p h 1^{-1-}$ mice (Figure 2E).

\section{Increased Generalized Bone Resorption and 0steoclast Differentiation in Arthritic Tph1 $1^{-/-}$Mice}

Experiments were performed to determine whether the increased bone resorption observed in $T p h 1^{-1-}$ mice occurred only into the inflamed articulation or whether it was a generalized phenomenon. We evaluated the bone structure on the femoral metaphysis by micro-CT
(Figure 3A). In a context of arthritis, the trabecular $\mathrm{BV} / \mathrm{TV}$ ratio was specifically decreased in $T p h 1^{-1-}$ mice. Trabecular separation was significantly higher $(+15.25 \%$ WT versus $\left.+29.41 \% \mathrm{Tphl}^{-1-} ; P<0.0001\right)$ in $T p h 1^{-1-}$ mice with arthritis (Figure 3B). D-pyridinoline, a systemic marker of bone resorption, was lower at day 0 in the $T p h 1^{-1-}$ mice. However, after the onset of arthritis, D-pyridinoline was increased in $T p h 1^{-1-}$ mice but unchanged in WT mice (Figure 3C). We further assessed osteoclast differentiation from spleen cells in the presence of macrophage colony-stimulating factor and increasing doses of RANK-L. At baseline and in accordance with our previous results, ${ }^{15}$ there was a reduced osteoclast differentiation in $T p h 1^{-1-}$ mice at all the RANK-L doses tested. In contrast, arthritic $T p h 1^{-1-}$ mice had greater osteoclast differentiation at all the doses of RANK-L tested (Figure 3, D and E).

\section{Increased Proinflammatory Cytokine Production in Arthritic Tph1 ${ }^{-/-}$Mice}

To characterize the mechanism underlying the increase in osteoclastic bone resorption in $T p h 1^{-1-}$ mice, we assessed the associated immune response. The concentration of CII-specific IgG1 was similar in both genotypes, but the concentration of CII-specific IgG2a was higher in $T p h 1^{-1-}$ mice, resulting in a markedly increased $\mathrm{IgG} 2 \mathrm{a} / \mathrm{IgG} 1$ ratio (Figure 4A). Because a switch to the $\mathrm{IgG} 2$ isotype is strongly associated with a Th1 response, we measured the Th1 and Th2 
A
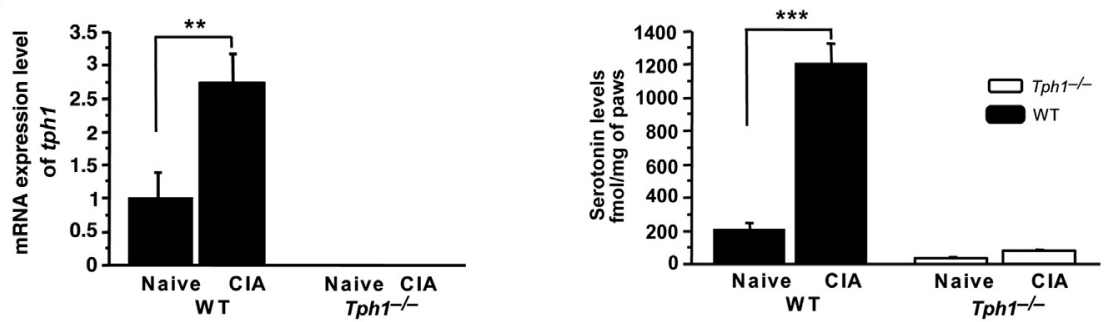

B
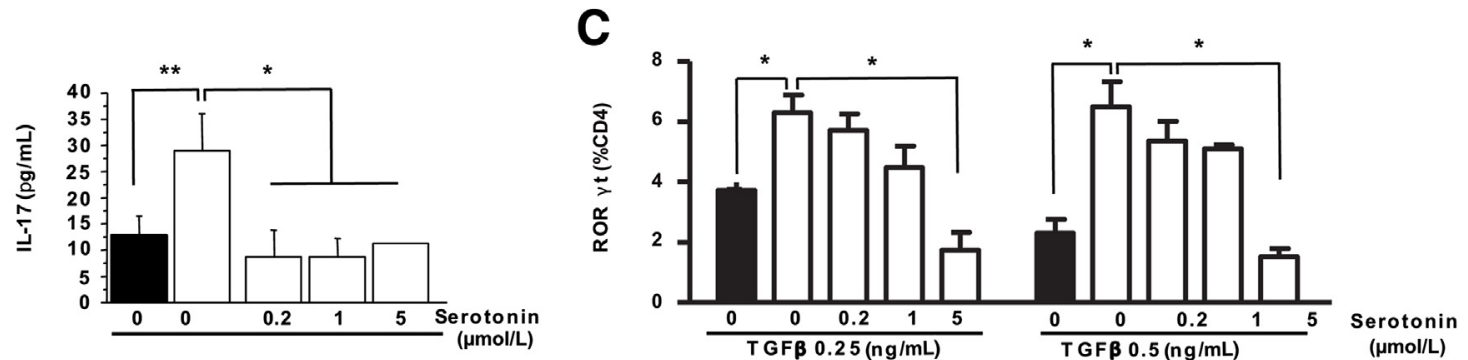

D
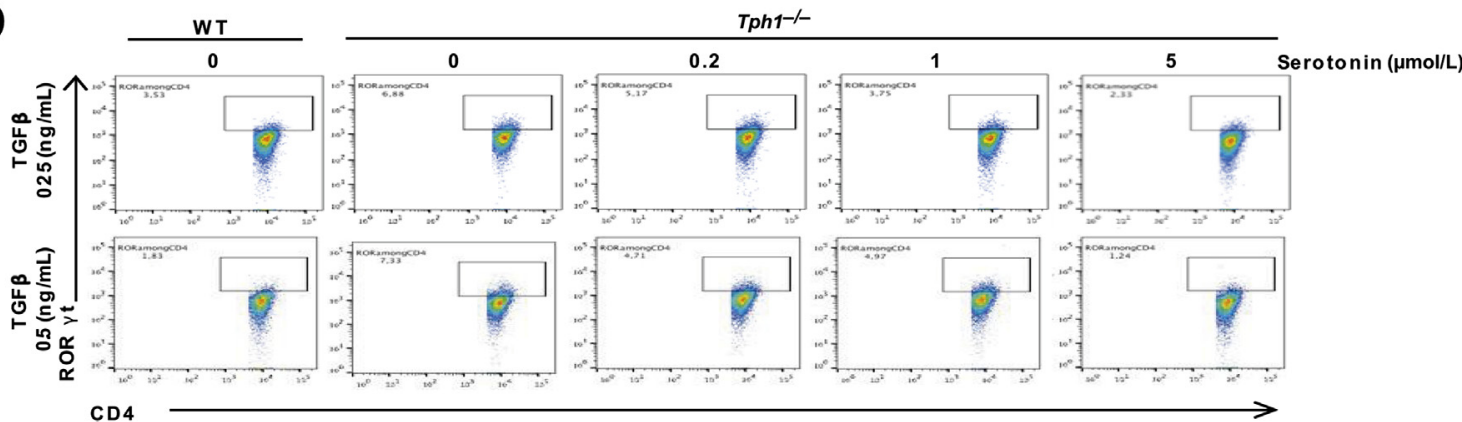

Figure 6 High levels of IL-17 and ROR $\gamma \mathrm{t}$ in arthritic Tph1 ${ }^{-1-}$ mice are reversed by serotonin. A: The relative expression of Tph1 and the 5-HT levels were assessed in the paws at baseline (naïve) and 36 days after the induction of collagen-induced arthritis (CIA) in wild-type (WT) and Tph1 ${ }^{-/-}$mice. Level of mRNA for TPH1 was not detectable in naïve or treated CIA Tph1 ${ }^{-1-}$ mice. B: Splenocytes of WT (black bars) and Tph1 $1^{-/-}$(white bars) mice were cultured with $50 \mu \mathrm{g} / \mathrm{mL}$ of type II collagen in the presence or absence of 5 -HT for 3 days and analyzed by enzyme-linked immunosorbent assay to measure the secretion of IL-17 into the culture supernatants. C: T cells isolated from the lymph nodes of WT (black bars) and Tph1 ${ }^{-1-}$ mice (white bars) were cultured under Th17-polarizing conditions in the presence or absence of serotonin for 3 days and analyzed by flow cytometry using the anti-ROR $r t$ antibody. D: Plots from one representative experiment indicate the percentage of ROR $\gamma t$ cells among $\mathrm{CD}^{+} \mathrm{T}$ cells. Data are expressed as means $\pm \mathrm{SEM}$ from two experiments (B and D). $n=7$ to 8 per group (A); $n=8$ WT mice and $n=7$ Tph $1^{-1-}$ mice (B); $n=3$ WT mice and $n=3$ Tph $1^{-1-}$ mice $(\mathbf{C}) .{ }^{*} P<0.05,{ }^{* *} P<0.005$, and ${ }^{* * *} P<0.0005$.

cytokines at the site of inflammation in the paws. $T p h 1^{-1-}$ mice had higher levels of TNF- $\alpha$ and IFN- $\gamma$, whereas the level of IL-4 was lower, indicating a stronger Th1 response in $T p h 1^{-1-}$ mice. Finally, the level of IL-17 was higher in $T p h 1^{-1-}$ mice than in arthritic WT mice (Figure 4B).

Increase in the Percentages of Th17 and Decrease in the Percentages of Treg Cells in the Lymph Nodes of Arthritic Tph1 ${ }^{-/-}$Mice

To gain insight into the mechanism underlying the increase in IL-17, we assessed the T-cell profiles in the draining lymph nodes of WT and $T p h 1^{-1-}$ mice. Flow cytometry analysis revealed comparable rates of $\mathrm{CD}^{+}$in the two genotypes. We observed a decrease in the percentage of $\mathrm{FoxP}^{+}$and more specifically in that of the FoxP $3^{+} \mathrm{CD} 25^{\text {high }}$ subset in lymph nodes of $T p h 1^{-1-}$ mice. Using intracellular staining for IL-17, a marked increase in the proportion of IL-17 stained cells was observed in $T p h 1^{-1-}$ mice (Figure 5, A and B). Interestingly, a similar trend was seen in the lymph nodes of naive $T p h l^{-1-}$ mice in which the percentage of FoxP $3{ }^{+} \mathrm{CD} 25^{\text {high }}$ lymphocytes was slightly lower than in the WT mice (Figure $5 \mathrm{C}$ ). Despite the inflammatory context observed in $T p h 1^{-/-}$mice, no difference was observed in the IL-6 levels in $T p h 1^{-/-}$ compared with WT mice (Figure 4B), ruling out the implication of this inflammatory cytokine in the alteration in the T-regulatory (Treg) cell/Th17 balance.

\section{Ex Vivo 5-HT Reverses Th17 Cell Differentiation in Arthritic Tph1 ${ }^{-/-}$Mice}

To provide further evidence that 5-HT was directly involved in the immunologic profile observed in arthritic $T p h 1^{-1-}$ mice, we assessed Tphl expression and the levels of 5-HT in the paws of WT mice with and without arthritis. In the 

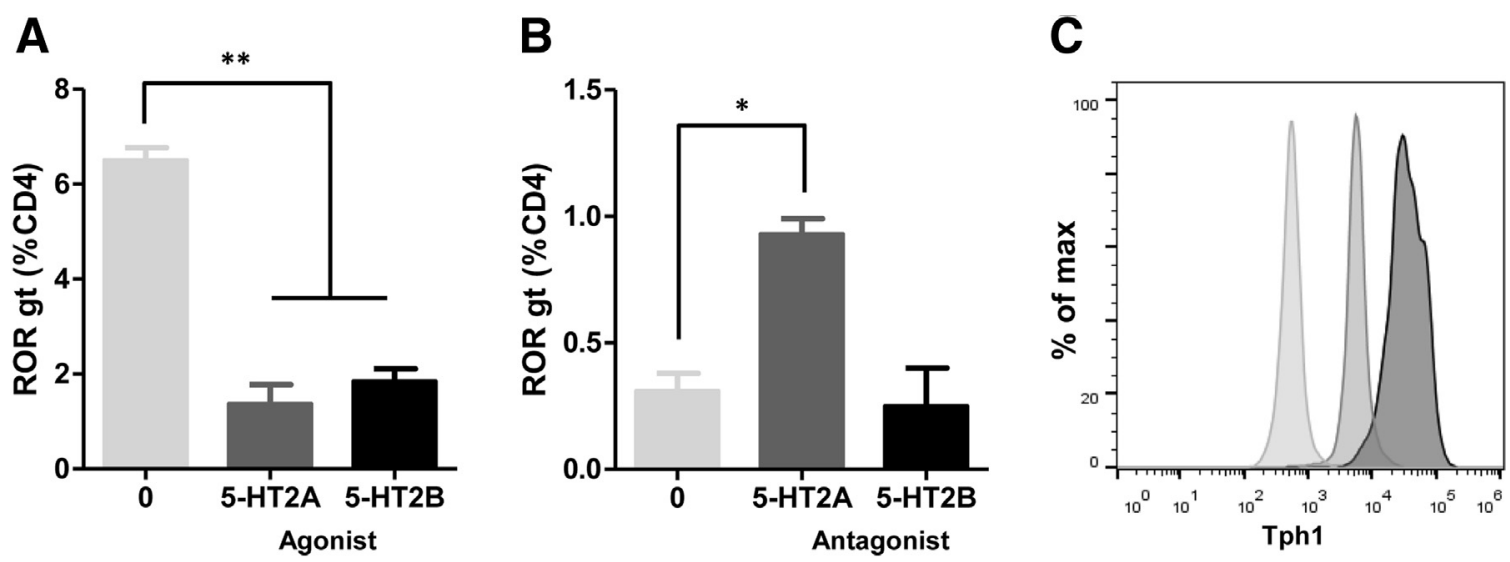

Figure 7 Serotonin regulates the Th17/T-regulatory cell balance by signaling through the 5-HT2A and 5-HT2B receptors present on T cells. A: Splenocytes of $\mathrm{Tph}^{-1-}$ mice were cultured under Th17-polarizing conditions in the presence or absence of 5-HT receptor agonists for 3 days and analyzed by flow cytometry using the anti-RORyt antibody. B: T CD4 ${ }^{+}$cells $\left(\mathrm{CD}^{+}{ }^{+}\right.$FoxP3 $3^{-}$) from wild-type (WT) FoxP3 GFP mice were sorted, stimulated by transforming growth factor- $\beta$, cultured in the presence of antagonists of 5-HT receptors for 3 days, and analyzed by flow cytometry using the anti-ROR t antibody. C: Human activated CD3/CD28 lymphocytes were cultured with or without parachlorophenylalanine, and the presence of the Tph1 protein was assessed by FACS analysis using the Tph1 antibody. Staining of T lymphocytes cultivated without (dark grey) or with (medium grey) the Tph inhibitor was compared with an isotype control (light grey). Data are expressed as means \pm SEM from two experiments. $n=4$ Tph $1^{-1-}$ mice $(\mathbf{A}) ; n=2$ WT FoxP3 GFP mice $(\mathbf{B})$. ${ }^{*} P<0.05, * * P<0.005$.

WT mice, we observed a sixfold increase in 5-HT level in the paws in a context of arthritis, correlated with an increase in Tphl expression (Figure 6A). We investigated whether 5-HT could directly modify the Th17 pattern. First, total splenocytes from WT and $T p h 1^{-1-}$ mice with CIA were stimulated in vitro with type II collagen. IL-17 level was significantly higher in $T p h 1^{-1-}$ spleen cell culture supernatants than in those of WT cells. In this setting, adding 5-HT to the culture medium reduced the level of IL-17 to the WT level (Figure 6B). Second, total lymph node cells of arthritic $T p h 1^{-1-}$ and WT mice were stimulated in the presence of optimal doses of TGF- $\beta$, and Th17 cell differentiation was assessed according to expression of ROR $\gamma \mathrm{t}$ transcription factor in T CD4 lymphocytes. In the presence of TGF- $\beta$, the percentage of ROR $\gamma t$ was higher in $T p h 1^{-1-}$ cells. Addition of $5-\mathrm{HT}$ to the cultures at doses of $5 \mu \mathrm{mol} / \mathrm{L}$ was able to reduce the number of ROR $\gamma \mathrm{t}$ cells of the $T p h 1^{-1-}$ mice to that found in the WT mice (Figure 6C).

\section{Serotonin Regulates the Th17/Treg Cell Balance by Signaling through the 5-HT2A and 5-HT2B Receptors Present on T Cells}

To identify through which receptors the effect of 5-HT are mediated, splenocytes from $T p h 1^{-1-}$ mice were cultured as previously described with TGF- $\beta$ supplemented medium in the presence or absence of 5-HT receptor agonists. ROR $\gamma \mathrm{t}$ expression in T CD4 lymphocytes was analyzed by flow cytometry after 3 days. We observed that both 5-HT2A and 5-HT2B receptor agonists decreased the level of ROR $\gamma \mathrm{t}$ expression in $\mathrm{CD}^{+} \mathrm{T}$ cells of $T p h 1^{-1-}$ mice (Figure 7A). In addition, we analyzed the 5-HTR antagonist effect on a purified $\mathrm{T} \mathrm{CD}^{+}{ }^{+}$FoxP3 $^{-}$population sorted from the spleen of FoxP3 GFP WT mice. T $\mathrm{CD} 4{ }^{+}$FoxP3 cells were stimulated ex vivo by the same doses of TGF- $\beta$ and cultured in the presence or absence of antagonists of 5-HT receptors for 3 days and analyzed by flow cytometry using the antiROR $\gamma t$ antibody. The 5-HT2A receptor antagonist was able to increase the level of ROR $\gamma$ t, whereas antagonists of the 5-HT2B receptor failed to do so (Figure 7B).

On the basis of our data indicating a significant increase in 5-HT level in the paws of WT mice in a context of CIA, we determined whether activated $\mathrm{T}$ cells could be a source of 5-HT. Activated (CD3/CD28) human T lymphocytes were cultured in the presence or absence of a Tph inhibitor (PCPA), and the presence of the Tph1 protein was assessed by FACS analysis using the Tph1 antibody. Figure 7C shows a specific binding of anti-Tph1 monoclonal antibody to the Tph1 protein on activated $(\mathrm{CD} 3 / \mathrm{CD} 28)$ human $\mathrm{T}$ lymphocytes, whereas a noticeable shift to the left was observed when human $\mathrm{T}$ lymphocytes were cultivated with the Tph inhibitor, suggesting that activated human T lymphocytes can synthesize 5-HT.

\section{Discussion}

Numerous studies have found that autoimmunity plays an important part in RA. ${ }^{16-18}$ Likewise, 5-HT has been associated with regulation of immunoinflammatory pathways, and changes in nonneuronal 5-HT levels and signaling have been reported in individuals with arthritis. ${ }^{19}$ Our findings indicate for the first time, to our knowledge, that 5-HT could be directly implicated in RA physiopathology. Using the welldefined CIA model in 5-HT-deficient mice, we found that after the induction of arthritis, the absence of peripheral 5-HT exacerbates the clinical score, amplifies osteoclast differentiation, and modulates the inflammatory response, whereas the addition of 5-HT in ex vivo cultures restore the Th17 profile. 
Chronic inflammation during RA leads to bone destruction, and osteoclasts play a key role in the bone erosion of arthritis. Studies have established a connection between osteoclastic bone resorption and the immune system in arthritis via the cross talk between $\mathrm{T}$ lymphocytes and osteoclasts. $^{20-22}$ We found that osteoclast number and activity were both markedly higher in the 5-HT-deficient mice with arthritis. Higher resorption was detected at the affected joints and remote sites. The osteoclastic phenotype observed in arthritic $T p h 1^{-1-}$ mice was associated with higher levels of IL-17 in the paws and Th17 cells in the lymph nodes. In addition, we confirmed our previous results that in the absence of Tphl bone resorption and osteoclastogenesis were decreased in naive mice. ${ }^{15}$ In arthritis, however, the absence of Tphl was associated to high inflammatory cytokine rates and increased osteoclast differentiation, thereby reversing the baseline phenotype.

A Th1/Th2 cytokine imbalance has been observed in patients with RA and in the CIA model. ${ }^{11,23}$ In addition, it is known that Th17 is a pathogenic subset of $\mathrm{CD}^{+} \mathrm{T}$ cells in $\mathrm{RA},{ }^{24}$ CIA development is markedly reduced in 1117 deficient mice, and antibody blockade of IL-17 dampens CIA inflammation. ${ }^{25,26}$ Likewise, in the paws of $T p h 1^{-1-}$ mice, we observed higher levels of the Th1 cytokine TNF- $\alpha$ and lower levels of IL-4, a Th2 cytokine. We also observed higher levels of Th17 lymphocytes in $T p h 1^{-1-}$ lymph nodes, whereas the percentage of FoxP $3^{+}$Treg cells was decreased. Moreover, the level of IL-17 observed was higher in the paws of $T p h 1^{-1-}$ mice with arthritis independently of any IL- 6 increase. Levels of FoxP3 ${ }^{+} \mathrm{T}$ cells were slightly but significantly lower in the lymph nodes of naive $T p h 1^{-1-}$ mice, suggesting that in $T p h 1^{-1-}$ mice the lack of 5-HT could already dampen production of Treg cells at baseline. However, the abnormal T-cell differentiation present in naive mice became clinically evident only after the induction of arthritis. Altogether, our data indicate that 5-HT-deficient mice are characterized by a relative, dampened expansion of Treg cells associated with an enhanced shift toward a Th17 phenotype, a situation previously described in arthritis. ${ }^{27}$

Because previous in vitro studies have found that 5-HT through its receptors can have a direct effect on immune cells, ${ }^{28-30}$ we next examined whether the increased Th17 phenotype, observed in 5-HT-deficient mice with arthritis, was related to a direct action of 5-HT on T lymphocytes. We performed ex vivo cultures using splenocytes from $T p h 1^{-1-}$ and WT mice using either 5-HT or agonist and antagonists of 5-HT receptors. As expected, a higher level of IL-17 was secreted in $T p h 1^{-/-}$splenocytes cultures, and the Th17 polarization could be reduced by adding physiologic doses of 5-HT. In the presence of TGF- $\beta$, the shift in the differentiation of lymph node $\mathrm{T}$ cells toward a Th17 profile was increased in $T p h 1^{-1-}$ mice and restored to a WT level in the presence of 5-HT or of the 5-HT2AR and 5-HT2BR agonists. Finally, analysis of the purified population of $\mathrm{CD}^{+}$ FoxP3 $^{-}$(non-Treg cells) sorted from the WT FoxP3 GFP mouse strain, stimulated with 5-HT receptor antagonists, suggests the involvement of the 5-HT2A receptor in the shifting of $\mathrm{T}$ cells toward the Th17 pattern and the development of arthritis. Given that both the 5-HT2A and 5-HT2B receptors play similar effect, it is somewhat puzzling that only the 5-HT2A receptor antagonist was able to increase the level of ROR $\gamma$ t. We can speculate that antagonists have various patterns of efficacy and that the 5-HT2B antagonist is less potent. Then again, the data argue that after activation of immunoinflammatory pathways and the onset of autoimmune reactions as in CIA, the effect mediated by 5-HT is directly via the 5-HT2A receptor present on CD4 $\mathrm{T}$ non-Treg cells to induce Treg cell proliferation. Consistent with this, there is substantial evidence in the literature that the 5-HT2A receptor is involved in human RA. For instance, a correlation between the severity of the disease and a lower density of the 5-HT2A receptors was found in a cohort of patients with RA. In addition, a genetic polymorphism of the $5 H T 2 A$ receptor gene, associated with susceptibility for RA, was found to influence the proinflammatory cytokine response of $\mathrm{T}$ cells and monocytes. ${ }^{31-34}$

From the experiment with the Tph1 inhibitor, we next found that $\mathrm{T}$ cells contain endogenous $\mathrm{Tph} 1$ activity and could therefore be a major source of 5-HT. Along that line, previous reports have found that murine activated $\mathrm{T}$ cells are capable of 5-HT synthesis. ${ }^{28}$ We extended these findings and found that activated human $\mathrm{T}$ lymphocytes can also synthesize 5-HT. Taken together, these data suggest that local 5-HT synthesis by lymphocyte T could signal through 5-HT receptors on $\mathrm{T}$ cells in an autocrine fashion and prevent a Th17 polarization and arthritis development.

In summary, our study highlights that 5-HT has a direct regulatory role in arthritis mainly through the Th17/Treg cell balance and osteclastogenesis regulation. The development of treatments that target 5-HT or 5-HT receptors could represent an exciting prospect to regulate the immune response in RA and open new perspectives to improve the therapeutic options for patients.

\section{Acknowledgments}

We thank Pascale Chanterenne and Clara Bernard for maintaining the mouse colony and Agnès Ostertag, Caroline Marty, and Elisa Bayard for their excellent technical assistance.

Y.C.-A., T.C., J.C., M.C., H.L., R.R., and F.C. performed experiments; Y.C.-A., T.C., C.C., J.C., M.C., H.L., M.D., F.C., M.-C.D.V. analyzed results; and Y.C.-A., T.C., F.C., M.-C.D.V. designed the experiments and wrote the manuscript.

\section{References}

1. Blalock JE: The syntax of immune-neuroendocrine communication. Immunol Today 1994, 15:504-511 
2. Gonzalez-Rey E, Chorny A, Delgado M: Regulation of immune tolerance by anti-inflammatory neuropeptides. Nat Rev Immunol 2007, 7:52-63

3. Berger M, Gray JA, Roth BL: The expanded biology of serotonin. Annu Rev Med 2009, 60:355-366

4. Amireault P, Sibon D, Côté F: Life without peripheral serotonin: insights from tryptophan hydroxylase 1 knockout mice reveal the existence of paracrine/autocrine serotonergic networks. ACS Chem Neurosci 2013, 4:64-71

5. Côté F, Thevenot E, Fligny C, Fromes Y, Darmon M, Ripoche MA, Bayard E, Hanoun N, Saurini F, Lechat O, Dandolo L, Hamon M, Mallet J, Vodjdani G: Disruption of the nonneuronal tph1 gene demonstrates the importance of peripheral serotonin in cardiac function. Proc Natl Acad Sci U S A 2003, 100:13525-13530

6. Walther DJ, Peter JU, Bashammakh S, Hörtnagl H, Voits M, Fink H, Bader M: Synthesis of serotonin by a second tryptophan hydroxylase isoform. Science 2003, 299:76

7. Gutknecht L, Kriegebaum C, Waider J, Schmitt A, Lesch KP: Spatiotemporal expression of tryptophan hydroxylase isoforms in murine and human brain: convergent data from Tph2 knockout mice. Eur Neuropsychopharmacol 2009, 19:266-282

8. Ahern GP: 5-HT and the immune system. Curr Opin Pharmacol 2011, $11: 29-33$

9. Mossner R, Lesch KP: Role of serotonin in the immune system and in neuroimmune interactions. Brain Behav Immun 1998, 12: 249-271

10. Nowak EC, de Vries VC, Wasiuk A, Ahonen C, Bennett KA, Le Mercier I, Ha DG, Noelle RJ: Tryptophan hydroxylase-1 regulates immune tolerance and inflammation. J Exp Med 2012, 209: $2127-2135$

11. Bevaart L, Vervoordeldonk MJ, Tak PP: Evaluation of therapeutic targets in animal models of arthritis: how does it relate to rheumatoid arthritis? Arthritis Rheum 2010, 62:2192-2205

12. Komatsu N, Takayanagi H: Inflammation and bone destruction in arthritis: synergistic activity of immune and mesenchymal cells in joints. Front Immunol 2012, 3:77

13. Lin H, Ah Kioon MD, Lalou C, Larghero J, Launay JM, Khatib AM, Cohen-Solal M: Protective role of systemic furin in immune responseinduced arthritis. Arthritis Rheum 2012, 64:2878-2886

14. Saidenberg-Kermanac'h N, Bessis N, Lemeiter D, Fournier C, Boissier MC: Interleukin-4 cellular gene therapy and osteoprotegerin decrease inflammation-associated bone resorption in collagen-induced arthritis. J Clin Immunol 2004, 24:370-378

15. Chabbi-Achengli Y, Coudert AE, Callebert J, Geoffroy V, Côté F, Collet C, de Vernejoul MC: Decreased osteoclastogenesis in serotonindeficient mice. Proc Natl Acad Sci U S A 2012, 109:2567-2572

16. Firestein GS: Evolving concepts of rheumatoid arthritis. Nature 2003, 423:356-361

17. Notley CA, Ehrenstein MR: The yin and yang of regulatory T cells and inflammation in RA. Nat Rev Rheumatol 2010, 6:572-577

18. Schett G, Gravallese E: Bone erosion in rheumatoid arthritis: mechanisms, diagnosis and treatment. Nat Rev Rheumatol 2012, 8: 656-664

19. Voog U, Alstergren P, Eliasson S, Leibur E, Kallikorm R, Kopp S: Progression of radiographic changes in the temporomandibular joints of patients with rheumatoid arthritis in relation to inflammatory markers and mediators in the blood. Acta Odontol Scand 2004, 62: $7-13$

20. Sato K, Suematsu A, Okamoto K, Yamaguchi A, Morishita Y, Kadono Y, Tanaka S, Kodama T, Akira S, Iwakura Y, Cua DJ, Takayanagi $\mathrm{H}$ : Th17 functions as an osteoclastogenic helper T cell subset that links $\mathrm{T}$ cell activation and bone destruction. J Exp Med 2006, 203:2673-2682

21. Zwerina K, Koenders M, Hueber A, Marijnissen RJ, Baum W, Heiland GR, Zaiss M, McLnnes I, Joosten L, van den Berg W, Zwerina J, Schett G: Anti IL-17A therapy inhibits bone loss in TNFalpha-mediated murine arthritis by modulation of the T-cell balance. Eur J Immunol 2012, 42:413-423

22. Lubberts E, Koenders MI, Oppers-Walgreen B, van den Bersselaar L, Coenen-de Roo CJ, Joosten LA, van den Berg WB: Treatment with a neutralizing anti-murine interleukin-17 antibody after the onset of collagen-induced arthritis reduces joint inflammation, cartilage destruction, and bone erosion. Arthritis Rheum 2004, 50:650-659

23. Chulze-Koops H, Kalden JR: The balance of Th1/Th2 cytokines in rheumatoid arthritis. Best Pract Res Clin Rheumatol 2001, 15:677-691

24. Komatsu N, Okamoto K, Sawa S, Nakashima T, Oh-hora M, Kodama T, Tanaka S, Bluestone JA, Takayanagi H: Pathogenic conversion of Foxp3 + T cells into TH17 cells in autoimmune arthritis. Nat Med 2014, 20:62-68

25. Nakae S, Nambu A, Sudo K, Iwakura Y: Suppression of immune induction of collagen-induced arthritis in IL-17-deficient mice. J Immunol 2003, 171:6173-6177

26. Hartgring SA, Willis CR, Alcorn D, Nelson LJ, Bijlsma JW, Lafeber FP, van Roon JA: Blockade of the interleukin-7 receptor inhibits collageninduced arthritis and is associated with reduction of $\mathrm{T}$ cell activity and proinflammatory mediators. Arthritis Rheum 2010, 62:2716-2725

27. Toh ML, Miossec P: The role of T cells in rheumatoid arthritis: new subsets and new targets. Curr Opin Rheumatol 2007, 19:284-288

28. O'Connell PJ, Wang X, Leon-Ponte M, Griffiths C, Pingle SC, Ahern GP: A novel form of immune signaling revealed by transmission of the inflammatory mediator serotonin between dendritic cells and T cells. Blood 2006, 107:1010-1017

29. León-Ponte M, Ahern GP, O’Connell PJ: Serotonin provides an accessory signal to enhance T-cell activation by signaling through the 5-HT7 receptor. Blood 2007, 109:3139-3146

30. Shajib MS, Khan W: The role of serotonin and its receptors in activation of immune responses and inflammation. Acta Physiol (Oxf) 2015, 213:561-574

31. Snir O, Hesselberg E, Amoudruz P, Klareskog L, Zarea-Ganji I, Catrina AI, Padyukov L, Malmström V, Seddighzadeh M: Genetic variation in the serotonin receptor gene affects immune responses in rheumatoid arthritis. Genes Immun 2013, 14:83-89

32. Kling A, Danell-Boman M, Stenlund H, Dahlqvist R: Association between the use of serotonin receptor 2A-blocking antidepressants and joint disorders. Arthritis Rheum 2009, 61:1322-1327

33. Kling A, Seddighzadeh M, Arlestig L, Alfredsson L, RantapääDahlqvist S, Padyukov L: Genetic variations in the serotonin 5-HT2A receptor gene (HTR2A) are associated with rheumatoid arthritis. Ann Rheum Dis 2008, 67:1111-1115

34. Kling A, Rantapää-Dahlqvist S, Stenlund H, Mjörndal T: Decreased density of serotonin 5-HT2A receptors in rheumatoid arthritis. Ann Rheum Dis 2006, 65:816-819 